\title{
Sedimentological and hydro-biogeochemical processes controlling arsenic behavior in the Holocene and upper Pleistocene aquifers of the central Yangtze River Basin
}

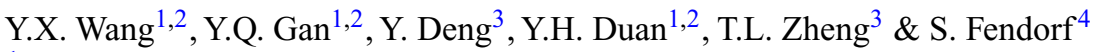 \\ ${ }^{1}$ State Key Laboratory of Biogeology and Environmental Geology, China University of Geosciences, \\ Wuhan, P.R. China \\ ${ }^{2}$ School of Environmental Studies, China University of Geosciences, Wuhan, P.R. China \\ ${ }^{3}$ Geological Survey, China University of Geosciences, Wuhan, P.R. China \\ ${ }^{4}$ Department of Earth System Science, Stanford University, Stanford, CA, USA
}

\begin{abstract}
Understanding the mechanism of geogenic arsenic mobilization from sediments to groundwater is important for safe and sustainable drinking water supply in the central Yangtze River Basin. Unlike the preponderance of observations within the deltas of South and Southeast Asia, groundwater As concentrations in the Holocene and upper Pleistocene aquifers at Yangtze vary by up to an order of magnitude seasonally. Bulk sediment geochemistry, arsenic associated mineralogical analysis and high-resolution OSL dating were applied to decipher the sedimentological controls on the formation of high arsenic aquifers. Sedimentological processes and paleoclimatic optima after the Last Glacial Maximum (LGM) have created favorable conditions for the formation of high-As aquifer systems. Intensive chemical weathering leading to sulfur depletion after the LGM could facilitate As enrichment in the Holocene and upper Pleistocene aquifers. Arsenic release depends on the iron mineralogy and microbial community in the aquifer sediments. Results of batch experiments and reactive transport modeling indicated that seasonal changes in surface water and groundwater levels drive changes in redox conditions. Seasonal variation of biogeochemical iron redox cycle may essentially control the mobilization/immobilization of As, while bacterial sulfate reduction could cause temporal attenuation of groundwater As concentration.
\end{abstract}

\section{INTRODUCTION}

Intake of geogenic arsenic (As) contaminated groundwater in sedimentary aquifers has caused serious health problems among tens of millions of people worldwide. Within river systems draining the Himalaya, tectonic movement, sedimentological processes and paleoclimatic optima after the Last Glacial Maximum (LGM) have created favorable conditions for the formation of high-As aquifer systems mainly in the late Pleistocene-Holocene deposits (McArthur et al., 2011; Wang et al., 2017). The Jianghan Plain in central Yangtze River Basins was documented with severe As contamination in the shallow aquifers (Deng et al., 2018), and As concentrations exhibited appreciable seasonal variations, with lower concentrations corresponding to lower water levels during the dry season and higher concentrations with increased water levels during the rainy season (Duan et al., 2015; Schaefer et al., 2016). However, the underlying mechanism responsible for the formation of high arsenic aquifers and the cause of seasonal release and retention of As between sediments and groundwater remain poorly understood. The major objective of this study was to understand the causes of the seasonal As concentration variation and the effects of Quaternary sediment deposition responding to sea level change since LGM on the arsenic enrichment in groundwater at Jianghan.

\section{METHODS}

\subsection{Study area}

Jianghan alluvial plain is located between the Yangtze River and its largest tributary, the Han River (Fig. 1).

\subsection{Sampling and analysis}

Sediment samples from six boreholes with depths up to $200 \mathrm{~m}$ in typical arsenic-affected area at Jianghan were collected for bulk geochemistry analysis, As and $\mathrm{Fe}$ speciation analysis, optical stimulated luminescence (OSL) dating, grain size analysis and mineralogy SEM-EDS analysis.

To simulate the arsenic concentration changes observed in the field, batch sediment incubation experiments were conducted under varying redox conditions by purging $\mathrm{N}_{2}$ and $\mathrm{O}_{2}$ gas respectively. Two sets of 


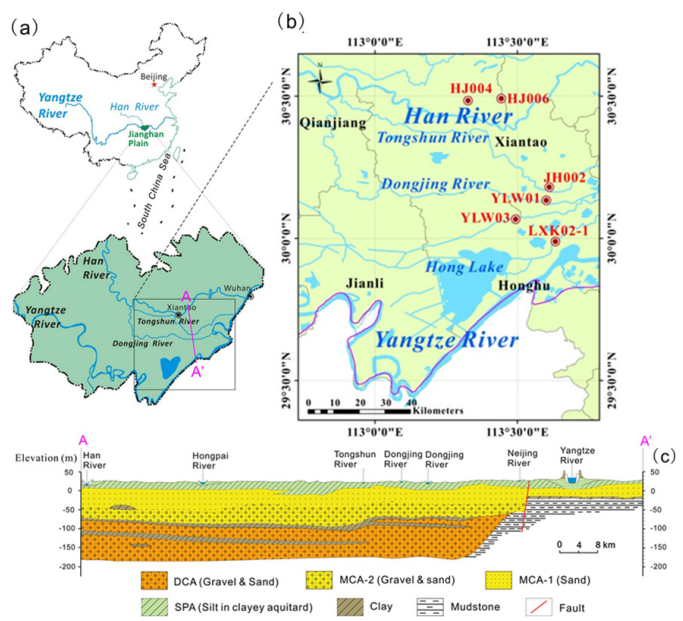

Figure 1. The location of sampling boreholes (red dots and numbers) and a typical hydrogeological section (A-A') across the study area in the Jianghan Plain. SPA, MCA and DCA are respectively shallow phreatic aquifer, middle and deep confined aquifers.

incubations were respectively subjected to two different patterns of redox cycles by switching the order of oxic and anoxic conditions: Anoxic-oxic-anoxic $(\mathrm{AOA})$ and oxic-anoxic-oxic $(\mathrm{OAO})$ incubations.

\section{RESULTS AND DISCUSSION}

\subsection{Sedimentological controls on the enrichment of arsenic in shallow aquifers since LGM}

Sea level in LGM was $120 \mathrm{~m}$ lower than today, a quick response of the Yangtze River $1000 \mathrm{~km}$ away from the estuary, which led to depositional break 40-20 ka ago. As was correlated with sulfur in the pre-LGM sediments and the pyrite was observed to be the main sink of As in the deep aquifer (deeper than $60 \mathrm{~m}$ ); by contrast, arsenic was closely correlated with iron in the post-LGM sediments. Results of sequential extraction of $\mathrm{Fe}$ indicated that $\mathrm{Fe}$ mainly occurs as iron-oxides in Holocene and upper Pleistocene sediments, and as siderite in middle-lower Pleistocene sediments.

The intense chemical weathering after LGM could be a major factor controlling As enrichment in the Holocene and upper Pleistocene aquifer. As the paleoclimate became warm and humid after LGM, intense chemical weathering led to sulfur depletion, secondary As-bearing $\mathrm{Fe} / \mathrm{Mn}$ oxides were formed and buried jointly with biodegradable NOM in the sediments.

\subsection{Redox fluctuation controls the seasonal variation of arsenic in groundwater}

Aqueous As and iron concentrations increase during anoxic periods and decrease during oxic periods in both AOA and OAO incubations. Dominant geochemical reactions deciphered from the results of our batch incubations explain the observed seasonal release and retention of As between sediments and groundwater at Jianghan. During groundwater recharging, oxygen and nitrate delivered to groundwater result in oxic condition in the aquifer. Fe(II) and As(III) are oxidized to form $\mathrm{Fe}(\mathrm{III})$ and $\mathrm{As}(\mathrm{V})$. Formation of fresh Fe(III) oxides provides additional sorption sites for As(III) and $\mathrm{As}(\mathrm{V})$, causing decrease in aqueous As concentration. During groundwater discharging, anoxic condition in the aquifer prevails due to limited input of oxygen. Fe(III) reductive dissolution and $\mathrm{As}(\mathrm{V})$ reduction cause release of As (mostly As(III)) into groundwater.

\section{CONCLUSIONS}

Sedimentological processes and paleoclimatic optima after LGM have created favorable conditions for the formation of high-As aquifer systems at Jianghan. Oscillation of redox conditions driven by temporal changes in surface and groundwater levels is the predominant factor affecting the observed seasonal As concentration variation in aquifers. Arsenic release depends on the iron mineralogy and microbial community in the aquifer sediments. Biogeochemical Fe-S redox cycle may essentially control the mobilization/immobilization of As.

\section{ACKNOWLEDGEMENTS}

The research was financially supported by the National Natural Science Foundation of China (Nos. 41521001 \& 41572226), China Geological Survey (Nos. 121201001000150121) and the 111 Program (State Administration of Foreign Experts Affairs \& the Ministry of Education of China, grant B18049).

\section{REFERENCES}

Deng, Y., Zheng, T., Wang, Y., Liu, L., Jiang, H. \& Ma, T. 2018. Effect of microbially mediated iron mineral transformation on temporal variation of arsenic in the Pleistocene aquifers of the central Yangtze River basin. Sci. Total Environ. 619-620: 1247-1258.

Duan, Y., Gan, Y., Wang, Y., Deng, Y., Guo, X. \& Dong, C. 2015.Temporal variation of groundwater level and arsenic concentration at Jianghan Plain, central China. J. Geochem. Explor. 149: 106-119.

McArthur, J.M., Nath, B., Banejee, D.M., Purohit, R. \& Grassineau, N. 2011. Palaeosol control on groundwater flow and pollutant distribution: the example of arsenic. Environ. Sci. Technol. 45(4): 1376-1383.

Schaefer, M.V., Ying, S.C., Benner, S.G., Duan, Y.,Wang, Y. \& Fendorf, S. 2016. Aquifer arsenic cycling induced by seasonal hydrologic changes within the Yangtze River Basin. Environ. Sci. Technol. 50(7): 3521-3529.

Wang, Y.X., Pi, K.F., Fendorf, S., Deng, Y.M. \& Xie, X.J. 2017. Sedimentogenesis and hydrobiogeochemistry of high arsenic Late Pleistocene-Holocene aquifer systems. Earth Sci. Rev. DOI:10.1016/j.earscirev.2017.10.007. 